\title{
The father of coronary artery bypass grafting: René Favaloro and the 50th anniversary of coronary artery bypass grafting
}

Faisal G. Bakaeen, MD, Eugene H. Blackstone, MD, Gösta B. Pettersson, MD, PhD, A. Marc Gillinov, MD, and Lars G. Svensson, MD, PhD

From the Center for Coronary Revascularization, Department of Thoracic and Cardiovascular Surgery, Heart and Vascular Institute, Cleveland Clinic, Cleveland, Ohio.

Funded by the Cleveland Clinic Department of Thoracic and Cardiovascular Surgery.

Received for publication July 19, 2017; revisions received Sept 20, 2017; accepted for publication Sept 28, 2017; available ahead of print March 28, 2018.

Address for reprints: Faisal G. Bakaeen, MD, Department of Thoracic and Cardiovascular Surgery, Cleveland Clinic, 9500 Euclid Ave/Desk J4-1, Cleveland, OH 44195 (E-mail: bakaeef@ccf.org).

J Thorac Cardiovasc Surg 2018;155:2324-8

$0022-5223 / \$ 36.00$

Copyright $\subset 2018$ by The American Association for Thoracic Surgery

https://doi.org/10.1016/j.jtcvs.2017.09.167

Dr René Favaloro performed his first coronary bypass operation in May 1967 with an interposed saphenous vein graft (SVG) and shortly thereafter used aortocoronary bypasses sutured proximally to the ascending aorta. This milestone endured because of the development of routine and safe coronary bypass techniques by Favaloro and his colleagues and the demonstration of coronary artery bypass grafting $(\mathrm{CABG})$ as a reproducible, lifesaving, and life-changing therapy for coronary artery disease (CAD). Its subsequent adoption worldwide has been sustained to this day. In the words of Dr Denton Cooley, "Although he [Favaloro] was always hesitant to carry the moniker of 'father' of coronary artery bypass surgery, he is the surgeon we should credit with introducing coronary bypass surgery into the clinical arena.",

The 50th anniversary of Favaloro's first CABG operation recognizes a long process of laboratory experimentation and pioneering isolated clinical cases in surgical myocardial revascularization. ${ }^{2}$ For this review, we have chosen to focus on technical aspects and challenges as they pertain to $\mathrm{CABG}$ and its evolution over time. We summarize the history of myocardial revascularization divided into 2 eras relative to Favaloro's first bypass operation. These eras are interrelated, with overlap in surgeons and techniques.

\section{MYOCARDIAL REVASCULARIZATION: PRE- FAVALORO}

In 1910, Dr Alexis Carrel ${ }^{3}$ described a series of canine experiments in which he devised means to treat CAD by creating a "complementary circulation" for the diseased native coronary arteries. No clinical translation occurred at the time, but he was awarded the Nobel Prize in Medicine. Experimental refinements of coronary arterial revascularization, including use of internal thoracic artery (ITA) grafts, were later reported by Murray and colleagues, ${ }^{4}$ Demikhov, and Goetz and colleagues ${ }^{6}$ in the 1950s and early 1960s.

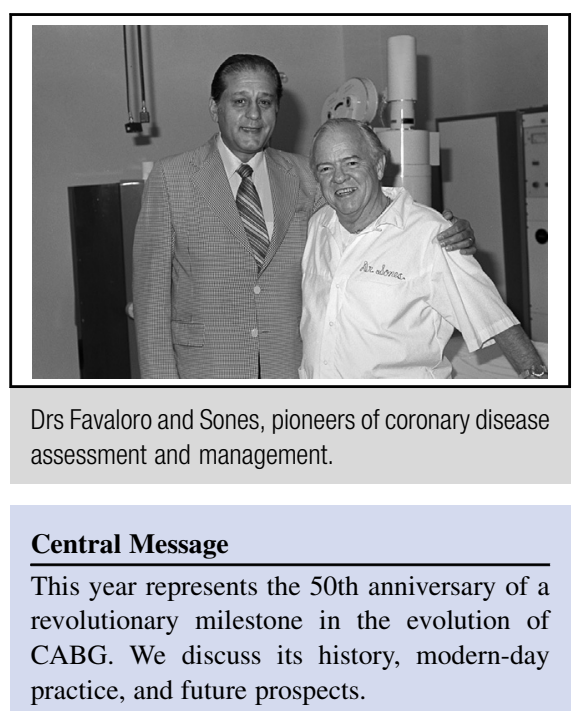

See Editorial Commentary page 2329.

\section{Clinical Interventions and Indirect \\ Revascularization}

Initial clinical interventions for ischemic heart disease were diverse and imaginative and included sympathectomy and indirect revascularization of the heart. ${ }^{2}$ The latter was attempted by Beck and Tichy, ${ }^{7}$ who created vascular adhesions between the epicardium and the myocardium using mechanical abrasion, often supplemented by some form of poudrage, or use of muscle or omental grafts as a source for neovascularization. ${ }^{8-10}$ Multiple needle punctures of the left ventricular wall were also tried to create new channels between the left ventricular cavity and the ischemic myocardium. ${ }^{11}$ None of these techniques was particularly effective or widely adopted.

In 1945, Vineberg and Miller ${ }^{12}$ capitalized on the unique properties of the ITA, including that it is usually spared from atherosclerosis, and reasoned that its branches would form collaterals with myocardial arterioles. They developed an experimental model and tracked the surviving patients who later died of other causes. They injected contrast medium in postmortem specimens demonstrating connections between the implant and the coronary arteries, but few surgeons took their work seriously. ${ }^{13}$

Dr Claude Schaeffer Beck decided by 1948 that direct revascularization of the heart could be accomplished by a 
graft between the descending aorta and the partially ligated coronary sinus. ${ }^{14,15}$ Initially the entire brachial artery was used as the conduit, but this was later replaced by a reversed SVG. The results were disappointing and the procedure shelved, and Beck reverted back to his technique of epicardial abrasion.

The advent of cardiopulmonary bypass and subsequent introduction of "elective cardiac arrest" in 1955, using the Melrose concept of injecting potassium citrate into the aortic root, made it possible to operate on a still heart with a bloodless field. ${ }^{13,16}$ This enhanced the feasibility and precision of cardiac operations, including CABG. At that time, however, all attempts at enhancing the blood supply to the heart were based on unproven concepts and were essentially "blind" interventions. What was missing was a diagnostic tool that could accurately locate and assess coronary artery lesions and prove the effectiveness of various revascularization procedures.

The breakthrough was the accidental injection by trainee Dr Royston C. Lewis of dye into the coronary arterial system on October 30, 1958, arresting the heart. ${ }^{17}$ His supervisor, Dr F. Mason Sones, Jr, successfully resuscitated the patient by having him cough. With this serendipitous event, Sones recognized the potential value of selective coronary angiography. ${ }^{18} \mathrm{He}$ subsequently demonstrated that this new procedure could precisely localize coronary lesions, creating the roadmap for revascularization. ${ }^{19}$ Favaloro remarked that without Sones' work, "all our efforts in myocardial revascularization would have been fruitless." 20

\section{Coronary Endarterectomy and Validation of the Vineberg Procedure}

Encouraged by the favorable endarterectomy experience in treating carotid and peripheral vascular disease and experimental endarterectomy in dogs and human hearts obtained at autopsy, segmental occlusions of major coronary arteries were approached by endarterectomy by Bailey and colleagues (1957), ${ }^{21}$ Longmire and colleagues (1958), ${ }^{22}$ Effler and colleagues (1964), ${ }^{23}$ and others thereafter. Inspection of the epicardium and palpation of the coronaries guided placement of the incision.

Endarterectomy was soon abandoned because of the shearing effect on the side branches and the often problematic distal dissection flap, ${ }^{23}$ and patch coronary arterioplasty, a technique described by Dr Åke Senning, was adopted. $^{24,25}$ In 1962, the Vineberg procedure was validated by selective ITA angiography of 3 patients operated on by Dr Wilfred Bigelow at Toronto General Hospital and referred to Cleveland. Their angiograms demonstrated patent ITAs with communications to the left anterior descending (LAD) coronary artery. Subsequently, Vineberg himself referred patients for angiography, and the Vineberg procedure became the revascularization modality of choice. ${ }^{13}$ By 1968, 2000 single and bilateral Vineberg procedures were performed at Cleveland Clinic, with $90 \%$ patency, half having a demonstrable connection with the obstructed coronary artery, and a substantial number demonstrating a contrast blush. ${ }^{26}$

\section{Direct Venous Graft}

Dr David Sabiston, Jr, performed the first CABG with venous grafting on April 4,1962, in a patient with an occluded right coronary artery (RCA). An SVG was taken from the leg and anastomosed from the ascending aorta to the RCA. ${ }^{27,28}$ At the end of the procedure, a pulse was present in both the graft and the RCA distally, but the patient had a stroke and died shortly thereafter. No angiographic documentation of this bypass was available. In 1964, Drs Edward Garrett, Jimmy Howell, and Michael DeBakey performed the first successful vein bypass in a patient with coronary obstruction as a bailout procedure for a complicated endarterectomy and published their report 9 years later with angiographic confirmation of graft patency. ${ }^{29}$

\section{Direct Internal Thoracic Artery Grafting}

In 1967, an article by Dr Vasilii Kolesov "Mammary Artery-Coronary Artery Anastomosis as Method of Treatment for Angina Pectoris" was published in the Journal. ${ }^{30}$ Dr Brian Blades, then Editor-in-Chief, wrote a foreword explaining that the procedure was at variance with prevailing concepts for treating ischemic heart disease in the United States and was therefore accompanied by an invited commentary by Dr Donald Brian Effler, Chairman of Thoracic and Cardiovascular Surgery at Cleveland Clinic, and a response by Kolesov. Interestingly, Dr George Green was finishing his cardiothoracic surgery residency under Dr Frank Spencer and had visited Effler that same year and shared radiographic images of his direct ITA-to-LAD bypass in dogs. Kolesov presented no angiographic data, and case selection was based on electrocardiography, stress testing, and direct inspection of the heart during surgery. Evaluation of the procedure was based on survival and symptom improvement.

Kolesov's early operations used a left anterior thoracotomy and were performed on a beating heart. By 1969, he reported on 45 patients who had undergone single and bilateral ITA grafting, with a mortality of $15 \%$. Kolesov might have performed the first direct thoracic-to-coronary sutured anastomosis. In that context, in May 1960, Dr Robert Goetz had performed a sutureless right ITA-to-RCA anastomosis using tantalum rings in a 38 -year-old man. ${ }^{6}$

\section{MYOCARDIAL REVASCULARIZATION: FROM FAVALORO TO THE PRESENT}

\section{All-Venous Coronary Artery Bypass Grafting}

After realizing the suboptimal results of patch coronary arterioplasty, Favaloro's first attempt at coronary vein 
grafting occurred on May 7, 1967, ${ }^{31,32}$ with an interposed SVG, and shortly afterward with bypasses from the ascending aorta. In 1968, Favaloro ${ }^{33}$ performed CABG for acute myocardial infarction and in the same year succeeded in combining reconstruction of the left ventricle and valve replacement with CABG. Important publications followed, documenting the largest $\mathrm{CABG}$ experience at the time, with operative mortality of less than $5 \%$ by $1970^{33,34}$ and $2 \%$ or less by the late $1970 \mathrm{~s}^{33}$ The low mortality, reproducibility, and relative simplicity caught the attention of the cardiovascular community and marked the start of the CABG revolution.

\section{The Rise of Internal Thoracic Artery Grafting}

At the end of 1970, impressed by the pioneering work of Green and colleagues, ${ }^{35}$ Favaloro and his team began using ITA-coronary anastomoses. Green used a microscope to construct these anastomoses, but Favaloro thought this approach cumbersome. Rather, he dissected the left ITA and anastomosed it to the LAD with only the help of the conventional magnifying surgical loupes that he used in his daily work. After Favaloro's departure from Cleveland Clinic in 1971, Dr Floyd Loop and colleagues standardized this method and demonstrated its excellent long-term outcomes in a seminal publication in $1986^{36}$ that established ITA-to-LAD grafting as a standard of care for CAD.

\section{CORONARY ARTERY BYPASS GRAFTING: THEN, NOW, AND BEYOND}

Favaloro's and Sone's deep understanding of CAD was reflected in numerous publications and was a product of the long hours they spent reviewing coronary angiograms at the Sones Library in the basement level of the Clinic. ${ }^{37,38}$ Their astute observations about the natural history of ischemic heart disease and its correlation with angiographic findings, size and significance of diseased vessels, severity of obstructive lesions, and the role of collateral circulation guided their and their colleagues' decisions about which patients might benefit from CABG. In addition, they put forth thoughtful explanations for the findings of early randomized trials that undervalued the benefit of CABG. ${ }^{33,37,39}$

In the words of Favaloro, "The introduction of PTCA [percutaneous transluminal coronary angioplasty] in 1977 deepened our responsibilities. Now our patients can follow three different roads (CABG, PTCA, or medical treatment). ${ }^{, 39}$ He meticulously analyzed differences between patients who qualified for both transcatheter intervention and $\mathrm{CABG}$ and thus were eligible for enrollment in trials, and patients who ended up in registries of the "everyday" CABG population. He reasoned that single-, double-, and triple-vessel disease classifications was inadequate to stratify CAD severity and used a scoring system when reading coronary angiograms. ${ }^{33}$ Many years later, the SYNTAX trial confirmed the importance of granular assessment of coronary lesion complexity in choosing between CABG and percutaneous coronary intervention and affirmed the incremental benefit of CABG in patients with complex left main and 3-vessel CAD (apart from those with CADassociated disease, such as diabetes). ${ }^{40}$ Today, additional physiologic and imaging modalities are further refining the prognostic importance of coronary lesions and patient selection for intervention. ${ }^{41}$

In one of his last comprehensive reviews of CABG in $1998,{ }^{39}$ Favaloro skillfully summarized the CABG evolution from the refinements of instruments and sutures to improvements in perfusion, myocardial protection, and perioperative care. He touched on important developments, including arterial conduits, off-pump surgery, minimally invasive surgery, and risk-adjusted outcomes, that importantly relate to current-day practice.

Favaloro $^{42}$ is credited with the evolution of bilateral ITA grafting, starting with the Vineberg procedure. His innovative ITA retractor facilitated exposure and harvesting. ${ }^{43} \mathrm{He}$ challenged the prevailing dogma that bilateral ITA harvesting resulted in sternal necrosis and popularized its use. In 2004, his successors associated bilateral ITA grafting with improved long-term survival compared with single ITA grafting. ${ }^{44}$

The Achilles heel of CABG is the suboptimal patency of SVGs. Favaloro ${ }^{39}$ and others understood that and incorporated additional arteries to supplement the ITA-to-LAD anastomosis in multivessel CABG. Furthermore, recent guidelines encourage multiarterial grafting. ${ }^{45}$ Despite the potential long-term benefits, only $5 \%$ of bypass operations in the United States are done with bilateral ITAs, ${ }^{45}$ and less than 5\% include radial artery grafting. Technical difficulties and lack of financial incentives are partly to blame. The absence of high-level evidence from randomized trials confirming a clear advantage of multiarterial grafting is unlikely to change the prevailing practice of left ITA-to-LAD grafting and vein grafts to the remaining targets.

With regard to off-pump CABG, Favaloro ${ }^{39}$ reminded us that $\mathrm{CABG}$ was performed on the beating heart during the early days by Kolesov. ${ }^{30} \mathrm{He}$ believed it would be extremely difficult to obtain the best possible results with this approach, especially with multiarterial grafting off-pump. Contrary to the findings of observational studies, randomized studies have not shown an advantage of the off-pump strategy in clinical outcomes. Nationally, use of off-pump procedures peaked in 2002 at $23 \%$, then declined to $17 \%$ by $2012 .{ }^{46}$

Favaloro commented on Calafiore and colleagues' large series ${ }^{47}$ of minimally invasive direct coronary artery bypass procedures. He speculated that minimally invasive direct coronary artery bypass may be combined with transcatheter interventions for non-LAD territories, adding that future development of thoracoscopic and other technologies to 
harvest conduits and create anastomoses may be in the pipeline. In essence, he foresaw the emergence of hybrid revascularization with or without robotic assistance. It is too early to pass judgment on these new modalities, and their use has been limited to niche practices thus far. ${ }^{48}$ In addition, lack of robust clinical and angiographic data and a number of technical, logistic, and cost-related barriers have hindered popularization of robotic CABG. ${ }^{49}$

Favaloro, Sones, and their colleagues embodied one of the earliest examples of the heart team. Favaloro explicitly remarked: “...for I have always believed in teamwork. 'We' is more important than 'I'. In medicine, the advances are always the result of many efforts accumulated over the years." 50

Favaloro's humanitarianism was reflected throughout his professional career and lives to this day through a foundation he established in Argentina dedicated to research, teaching, and treatment. He was also especially proud of his educational endeavors, as expressed in his 1994 memoir: "I have said on many occasions that when I am gone I would prefer to be remembered for my teaching rather than my surgical activities." ${ }^{, 1}$

Of note, despite his surgical prowess, Favaloro emphasized from the beginning that CABG was "only a palliative treatment" for CAD. He was a believer in secondary prevention and comprehensive risk-factor identification and management in combination with medical therapy to slow and possibly reverse atherosclerosis. ${ }^{39}$

Favaloro emphasized the improved outcomes of CABG over time despite operating on older and sicker patients. $\mathrm{He}$ touted the risk-adjusted outcomes in the Society of Thoracic Surgeons database, but cautioned about the unintended consequences of risk aversion and denial of care. The star rankings of CABG quality and public reporting have added an extra layer of scrutiny, but were deemed a necessary evolution to keep cardiac surgeons ahead of the game in the current healthcare environment. Indeed, the concept of risk-adjusted public reporting of results of therapy across medicine had its origin in the reporting of outcomes for $\mathrm{CABG}$.

The proposed implementation of episode payment models will usher in a new era of CABG care that not only emphasizes high-quality outcomes but also holds hospitals and clinicians financially responsible for expenses incurred during index hospitalizations and 90 days after discharge. Although improved care coordination is the stated rationale, cost reduction is the driving motivation. However, concerns regarding access, quality, and effectiveness of treatment are real. ${ }^{52}$ Risk-adjusted outcomes based on claims data will be used, and it will be difficult to adjust for extreme-risk patients; thus, hospitals willing to care for such patients may be at greatest financial risk. In addition, factoring in the quality of CABG itself and its long-term effectiveness is not part of the CABG episode payment models. For example, using guideline-directed multiarterial revascularization ${ }^{45}$ in appropriately selected patients may be more expensive in the short term but more costeffective in the long term. To handle these challenges, a more sophisticated risk-scoring and anticipated-benefit algorithm is required.

\section{CONCLUSIONS}

As we celebrate the 50th anniversary of Favaloro's first bypass operation, we are reminded of his innovative and brave spirit, as well as others who contributed to the advancement of CABG. Their thorough and meticulous work documenting the safety, effectiveness, and durability of CABG has secured its important role in the treatment of CAD to this day and for the foreseeable future. Over the years, CABG has survived the closest scrutiny of quality and clinical effectiveness, as well as the challenges posed by percutaneous coronary intervention and diminishing reimbursement. Advancements in CABG techniques have been incremental and steady but not disruptive. Unless new medical therapies can reverse coronary atherosclerosis, we are likely to still celebrate CABG (in some form or another) 50 years from now.

\section{Conflict of Interest Statement}

Authors have nothing to disclose with regard to commercial support.

\section{References}

1. Cooley DA. In memoriam. Tribute to Rene Favaloro, pioneer of coronary bypass. Tex Heart Inst J. 2000;27:231-2.

2. Jones DS. CABG at 50 (or 107?) - the complex course of therapeutic innovation. N Engl J Med. 2017;376:1809-11.

3. Carrel A. VIII. On the experimental surgery of the thoracic aorta and heart. Ann Surg. 1910;52:83-95.

4. Murray G, Porcheron R, Hilario J, Roschlau W. Anastomosis of systemic artery to the coronary. Can Med Assoc J. 1954;71:594-7.

5. Demikhov V. Experimental Transplantation of Vital Organs. Authorized translation from the Russian by Basil Haigh. New York: Consultant's Bureau; 1962.

6. Goetz RH, Rohman M, Haller JD, Dee R, Rosenak SS. Internal mammarycoronary artery anastomosis. A nonsuture method employing tantalum rings. $J$ Thorac Cardiovasc Surg. 1961;41:378-86.

7. Beck CS, Tichy VL. The production of a collateral circulation to the heart. Am Heart J. 1935; 10:849-73.

8. O'Shaughnessy L. Surgical treatment of cardiac ischaemia. Lancet. 1937;1: 185-94.

9. Vineberg AM, Kato Y, Pirozynski WJ. Experimental revascularization of the entire heart. Evaluation of epicardiectomy, omental graft, and/or implantation of the internal mammary artery in preventing myocardial necrosis and death of the animal. Am Heart J. 1966;72:79-93.

10. Friedbacker K. Omentum as source of nutrition to experimentally produced myocardial ischemia. Surg Gynecol Obstet. 1942;75:110-3.

11. Sen PK, Udwadia TE, Kinare SG, Parulkar GB. Transmyocardial acupuncture: a new approach to myocardial revascularization. J Thorac Cardiovasc Surg. 1965; 50:181-9.

12. Vineberg A, Miller G. Internal mammary coronary anastomosis in the surgical treatment of coronary artery insufficiency. Can Med Assoc J. 1951;64:204-10.

13. Effler DB. Chapter 1: History. In: Green GE, Singh RN, Sosa JA, eds. Surgical Revascularization of the Heart: The Internal Thoracic Arteries. Tokyo: IgakuShoin; 1991:1-17.

14. Beck CS, Stanton E, Batiuchok W, Leiter E. Revascularization of heart by graft of systemic artery into coronary sinus. J Am Med Assoc. 1948;137:436-42. 
15. McAllister FF, Leighninger D, Beck CS. Revascularization of the heart by vein graft from aorta to coronary sinus. Ann Surg. 1951;133:153-65.

16. Kolff WJ, Effler DB, Groves LK, Peereboom G, Aoyama S, Sones FM Jr. Elective cardiac arrest by the Melrose technic: potassium asystole for experimental cardiac surgery. Cleve Clin Q. 1956;23:98-104.

17. Sones FM Jr, Shirey EK, Proudfit WL, Westcott RN. Cine-coronary arteriography [abstract]. Circulation. 1959;20:773-4.

18. Meyers MA. "Cough, goddamn it!" The Pharos. 2016;79:27-30.

19. Sones FM Jr, Shirey EK. Cine coronary arteriography. Mod Concepts Cardiovasc Dis. 1962;31:735-8.

20. Hall RJ. In memorium: F. Mason Sones, Jr, M.D. Tex Heart Inst J. 1985;12:356-8.

21. Bailey CP, May A, Lemmon WM. Survival after coronary endarterectomy in man. J Am Med Assoc. 1957;164:641-6.

22. Longmire WP Jr, Cannon JA, Kattus AA. Direct-vision coronary endarterectomy for angina pectoris. $N$ Engl J Med. 1958;259:993-9.

23. Effler DB, Groves LK, Sones FM Jr, Shirey EK. Endarterectomy in the treatment of coronary artery disease. J Thorac Cardiovasc Surg. 1964;47:98-108.

24. Senning A. Strip grafting in coronary arteries. Report of a case. J Thorac Cardiovasc Surg. 1961:41:542-9.

25. Effler DB, Sones FM Jr, Favaloro R, Groves LK. Coronary endarterotomy with patchgraft reconstruction: clinical experience with 34 cases. Ann Surg. 1965;162:590-601.

26. Fergusson DJ, Shirey EK, Sheldon WC, Effler DB, Sones FM Jr. Left internal mammary artery implant-postoperative assessment. Circulation. 1968;37:II24-6.

27. Sabiston DC Jr. The development of surgery of the coronary circulation: the Bigelow lecture. Ann Surg. 1997;226:153-61.

28. Sabiston DC Jr. The William F. Rienhoff, Jr. Lecture. The coronary circulation. Johns Hopkins Med J. 1974;134:314-29.

29. Garrett HE, Dennis EW, DeBakey ME. Aortocoronary bypass with saphenous vein graft. Seven-year follow-up. JAMA. 1973;223:792-4.

30. Kolessov VI. Mammary artery-coronary artery anastomosis as method of treatment for angina pectoris. J Thorac Cardiovasc Surg. 1967;54:535-44.

31. Favaloro RG. Saphenous vein autograft replacement of severe segmental coronary artery occlusion: operative technique. Ann Thorac Surg. 1968;5:334-9.

32. Favaloro RG. The developmental phase of modern coronary artery surgery. Am J Cardiol. 1990;66:1496-503.

33. Favaloro RG. Direct myocardial revascularization: a 10 year journey. Myths and realities. Louis F. Bishop Lecture. Am J Cardiol. 1979;43:109-29.

34. Sheldon WC, Favaloro RG, Sones FM Jr, Effler DB. Reconstructive coronary artery surgery. Venous autograft technique. JAMA. 1970;213:78-82.

35. Green GE, Stertzer SH, Reppert EH. Coronary arterial bypass grafts. Ann Thorac Surg. 1968;5:443-50

36. Loop FD, Lytle BW, Cosgrove DM, Stewart RW, Goormastic M, Williams GW, et al. Influence of the internal-mammary-artery graft on 10-year survival and other cardiac events. N Engl J Med. 1986;314:1-6.
37. Favaloro RG. The present era of myocardial revascularization-some historical landmarks. Int J Cardiol. 1983;4:331-44.

38. Captur G. Memento for Rene Favaloro. Tex Heart Inst J. 2004;31:47-60.

39. Favaloro RG. Critical analysis of coronary artery bypass graft surgery: a 30-year journey. J Am Coll Cardiol. 1998;31:1B-63B.

40. Mohr FW, Morice MC, Kappetein AP, Feldman TE, Stahle E, Colombo A, et al. Coronary artery bypass graft surgery versus percutaneous coronary intervention in patients with three-vessel disease and left main coronary disease: 5-year follow-up of the randomised, clinical SYNTAX trial. Lancet. 2013;381:629-38.

41. Collet C, Onuma Y, Miyazaki Y, Morel MA, Serruys PW. Integration of noninvasive functional assessments with anatomical risk stratification in complex coronary artery disease: the non-invasive functional SYNTAX score. Cardiovasc Diagn Ther. 2017;7:151-8.

42. Favaloro RG. Double internal mammary artery implants: operative technique. $J$ Thorac Cardiovasc Surg. 1968;55:457-65.

43. Favaloro RG. Unilateral self-retaining retractor for use in internal mammary artery dissection. J Thorac Cardiovasc Surg. 1967;53:864-5.

44. Lytle BW, Blackstone EH, Sabik JF, Houghtaling P, Loop FD, Cosgrove DM. The effect of bilateral internal thoracic artery grafting on survival during 20 postoperative years. Ann Thorac Surg. 2004;78:2005-14.

45. Aldea GS, Bakaeen FG, Pal J, Fremes S, Head SJ, Sabik J, et al. The Society of Thoracic Surgeons clinical practice guidelines on arterial conduits for coronary artery bypass grafting. Ann Thorac Surg. 2016;101:801-9.

46. Bakaeen FG, Shroyer AL, Gammie JS, Sabik JF, Cornwell LD, Coselli JS, et al. Trends in use of off-pump coronary artery bypass grafting: results from the Society of Thoracic Surgeons adult cardiac surgery database. J Thorac Cardiovasc Surg. 2014;148:856-64.

47. Calafiore AM, Giammarco GD, Teodori G, Bosco G, D'Annunzio E, Barsotti A, et al. Left anterior descending coronary artery grafting via left anterior small thoracotomy without cardiopulmonary bypass. Ann Thorac Surg. 1996;61:1658-65.

48. Hiesinger W, Atluri P. Hybrid coronary revascularization: ready for prime time, but who should star? J Thorac Cardiovasc Surg. 2016;151: 1090-1.

49. Cao C, Indraratna P, Doyle M, Tian DH, Liou K, Munkholm-Larsen S, et al. A systematic review on robotic coronary artery bypass graft surgery. Ann Cardiothorac Surg. 2016;5:530-43.

50. Favaloro RG. Landmarks in the development of coronary artery bypass surgery. Circulation. 1998;98:466-78.

51. Favaloro RG. The Challenging Dream of Heart Surgery. Boston: Little, Brown and Company; 1994.

52. Bakaeen FG, Rich J, Svensson LG. Episode payment model for CABGopportunities and challenges. JAMA Surg. 2018;153:20. 